\title{
How Doctoral Students and Graduates Can Facilitate Boundary Spanning between Academia and Industry
}

\author{
Leena Kunttu, Essi Huttu, and Yrjö Neuvo
}

\author{
"This doctoral education program is an excellent example of ") \\ practical collaboration with universities. We can develop our \\ own internal competences with the newest scientific \\ knowledge. Moreover, we can familiarize our potential future \\ workforce with practical industrial $R \& D$ work and with its \\ challenges and innovation opportunities. This kind of jointly \\ organized doctoral program is, for us, a natural channel for \\ recruiting highly skilled experts from the academic world.
}

Industrial partner interviewed in this study

\begin{abstract}
The mobility of scientific competences from universities to industrial firms enables firms to absorb and utilize the knowledge developed in academia. However, too few young doctors are currently employed in industry, despite the fact that they could transfer and integrate valuable academic knowledge for industrial purposes and facilitate its utilization towards commercial ends. In this article, we investigate the role of doctoral students and graduates as academic boundary spanners by presenting three joint programs between universities and industrial players that facilitate and promote the industrial involvement of doctoral students and graduates. The cases highlight the meaning of university-industry collaboration in doctoral education and present practical examples of how industrial firms may facilitate the transfer of academic knowledge to industry through jointly organized doctoral education and postdoctoral mobility programs.
\end{abstract}

\section{Introduction}

The results of academic research developed towards commercial ends provide industrial firms with a way to improve their competitiveness, and thus effective knowledge transfer between academia and industry can be a powerful source of innovation (Laursen \& Salter, 2004; Perkmann et al., 2013; Siegel et al., 2004). The ability of an industry sector to utilize the knowledge of a highly educated workforce is an important factor in improving its innovative capacity and the economy overall (Weckowska, 2015). However, maintaining competitiveness and further strengthening it requires constant monitoring and analysis of new technological and operational trends. Intensifying international competition and accelerating speed of change require that industrial firms not only have the ability to implement the latest innovations, but also actively create new innovations (Gassmann et al., 2010).
One of the most essential ways of transferring knowledge is to facilitate the mobility of academics to industry and vice versa. Recruiting newly graduated doctors has been found to be an effective method of transferring and integrating the latest academic knowledge for industrial purposes (Kunttu, 2017). Doctors have the most up-to-date scholarly knowledge in their field, and they are capable of attacking demanding problems with scientific rigour. However, relatively few doctors are actually employed in industrial firms in Western Europe (Auriol et al., 2013), despite the fact that the countries in this region have graduated a rapidly increasing number of doctors in recent decades. For instance, in high-technology countries such as Finland and Sweden, only about $25-30 \%$ graduated doctors are employed in private sector.

When people move between academia and industry, they have to cross different organizational boundaries 


\section{How Doctoral Students and Graduates Can Facilitate Boundary Spanning between Academia and Industry Leena Kunttu, Essi Huttu, and Yrjö Neuvo}

(Rajalo \& Vadi, 2017), because the institutions operate under different environments and cultures caused by their own norms, motives, and values (Bruneel et al., 2010). For this reason, university-industry boundaries often represent obstacles to establishing close interactions between actors on either side. Reflecting this challenge, doctoral students working in universities often focus on relatively narrow topics defined by academic priorities, but without a clear connection to real-world industrial work (Kunttu, 2017). Therefore, facilitating practices for boundary spanning and relevant social processes are necessary to open new avenues for interaction and integration of doctoral students with an industrial environment.

Thus, boundary spanning is an important skill or behaviour for actors who actively aim at transferring academic knowledge between academia and industry (Ankrah \& Al-Tabbaa, 2015). These boundary actors may serve as a bridge between industrial firms ("customers") and academic institutions ("suppliers"), who operate in different environments with different motives, cultures, and actions (Siegel et al., 2004). The doctoral candidates and young doctors who engage in industrial domains represent boundary actors who may operate across the boundary between university and industry and thus help to transfer knowledge in both directions.

Previous research has highlighted the importance of the academic engagement and knowledge transfer in university-industry collaboration (Ankrah \& Al-Tabbaa, 2015; Ankrah et al., 2013; Perkmann et al., 2013), but this research falls short in its analysis of educational collaboration and in the role of students and graduates as boundary spanners. As indicated by Ankrah and Al-Tabbaa (2015) in their recent systematic literature review on university-industry collaboration: “...the impact of academic engagement in the process of UIC [university-industry collaboration] is almost overlooked. For example, none of the reviewed studies have addressed the consequences of this engagement on, for example, teaching and learning experience of students affiliated with universities that engaged with the industry. This line of research can provide supporting evidence to the intangible potential value of the UIC (Perkmann et al., 2013)."

To address this gap, this study intends to answer the following research questions:

- How can jointly organized doctoral education programs facilitate the mobility of doctoral students and graduates from academia to industry?

\section{- What kinds of boundary spanning practices are related to these programs?}

To address these questions, we present a case study investigating three doctoral education programs that focus on the mobility of doctoral graduates from academia to industry. All these programs aim at familiarizing the students with an industrial way of working and by providing them with real industrial problems to which they can apply their academic knowledge and problem-solving skills. By using these kinds of educational programs, the universities and industry are able together lowering the boundaries between these two types of institutions and facilitate effective knowledge transfer between them.

The remainder of the article is organized as follows. The following section describes three cases of doctoral education programs designed to facilitate boundary spanning between academia and industry. After that, we present and discuss our findings. Next, we highlight the practical implications of the findings. Finally, we offer conclusions.

\section{Three Cases of Boundary Spanning}

This study presents three cases of boundary spanning in the context of university-industry collaboration, as summarized in Table 1. The authors of this article are the main organizers of the courses described in the three cases (Case 1: Neuvo; Case 2: Kunttu; Case 3: Huttu) and are the main source of information about these cases. Additional data used in the case descriptions included interviews and feedback from the course participants as well as materials produced during the courses.

\section{Case 1: Bit Bang}

The first case presents the Bit Bang doctoral training course, which has been run annually throughout the full academic year at Aalto University, Finland, since 2008. This postgraduate course is built around a general theme specified every year. The course relies on multidisciplinary and multinational teamwork assignments in the area of the course theme, and top-class guest lectures from industry leaders. The course adapts Nokia's top management training program to the academic environment. The course aims at facilitating collaboration across disciplines and, what is even more important, provides a bridge between academic post-graduate studies and industrial real-world challenges. The students work on specific assignments in student teams under the supervision of experienced tutors, and they 


\section{How Doctoral Students and Graduates Can Facilitate Boundary Spanning between Academia and Industry Leena Kunttu, Essi Huttu, and Yrjö Neuvo}

Table 1. A summary of three cases of boundary spanning in university-industry collaboration

\begin{tabular}{llll}
\hline & Case 1 & Case 2 & Case 3 \\
\hline Activity name & Bit Bang & Nokia Mobile Imaging & PoDoCo Program \\
\hline University partners & Aalto University & $\begin{array}{l}\text { Tampere University of } \\
\text { Technology, Aalto University }\end{array}$ & Several universities in Finland \\
\hline Industrial partners & $\begin{array}{l}\text { Nokia and other Finnish } \\
\text { technology companies }\end{array}$ & Nokia & An industrial consortium \\
\hline Target group & $\begin{array}{l}\text { Doctoral students } \\
\text { Teamwork on course topics; } \\
\text { guest lectures from industry; } \\
\text { a week-long study tour }\end{array}$ & $\begin{array}{l}\text { Teamwork on course topics; } \\
\text { guest lectures from academia } \\
\text { and industry }\end{array}$ & $\begin{array}{l}\text { Research grant for a broad } \\
\text { research phase followed by a } \\
\text { targeted research phase } \\
\text { funded by the industrial } \\
\text { partner }\end{array}$ \\
\hline Deliverables & $\begin{array}{l}\text { Doctoral students academic report authored } \\
\text { by each student team }\end{array}$ & $\begin{array}{l}\text { Presentations and reports } \\
\text { Company-specific research } \\
\text { results }\end{array}$
\end{tabular}

Impact on students

Impact on companies
The majority of student participants were hired by industrial firms after doctoral graduation.

The companies benefitted from new scientific knowledge and relationship building with potential new employees. jointly author a report on their team-specific topic. The highlight of the course is a week-long intensive study tour to a globally recognized region of research, innovation, and business. Past locations for the study tour have included Shangai, Tokyo, Bangalore, New York, and California, and each tour includes both company and academic site visits. The course has been organized nine times, and the total number of participants has been about 200. The majority of the students have been hired by industrial firms after following their graduation, and many also still participate in the program as tutors or guest lecturers or are still actively involved by attending Bit Bang events. Papers produced by students during their Bit Bang collaboration have produced interesting results: many participants have gone on to write conference papers and journal articles based on the joint reports written in class.

\section{Case 2: Nokia Mobile Imaging}

The second case presents a series of company-specific university collaboration courses organized between Nokia and Finnish universities during 2008-2010. The purpose of the courses was to deepen understanding of topics related to image analysis and processing in mo- bile devices. The courses were built on the existing and quite intensive research collaboration between Nokia imaging software development and a consortium of Finnish university research groups. The main idea in organizing the courses was to facilitate effective knowledge transfer between Nokia's imaging $R \& D$ team and the university research groups on selected topics in mobile imaging. In this manner, the academics were encouraged to present the most recent research-based knowledge in this area, whereas the company R\&D staff brought their experience-based knowledge in the courses. The teaching was based on weekly meetings in which either a university professor or an $R \& D$ specialist from Nokia gave a lecture on a selected topic in their area of specialty. After the lecture, they all discussed the topic together. The team work was related to the course content and was based on a selected practical industrial problem, to which the teams were searching for a solution with the guidance of academic and industrial supervisors. The target audience for the courses was Nokia R\&D staff and university doctoral students. There also were doctoral students who already worked in Nokia R\&D, but who undertook doctoral studies after being encouraged by this kind of learning opportunity. 


\section{How Doctoral Students and Graduates Can Facilitate Boundary Spanning between Academia and Industry Leena Kunttu, Essi Huttu, and Yrjö Neuvo}

The doctoral students participating in the courses were given credits on the passed courses. The courses were organized in two consequent academic years around different themes. The theme for the first course was Mobile Imaging and for the second course theme was Image Quality. The total number of participants for both courses was about 60 people who were about equally divided between industrial R\&D staff and academics.

\section{Case 3: The PoDoCo program}

The third case, the PoDoCo (PostDocs in Companies) program, is a joint initiative of Finnish universities, industry, and foundations. The aim of the program is to support the transition of doctoral graduates into private sector careers and, at the same time, enhance the strategic renewal of companies. PoDoCo facilitates novel meetings and matches newly graduated doctors with companies, and it financially supports the collaboration projects between doctors and companies. Annually, the PoDoCo program receives almost one million Euros annually in funding from its nine participating foundations and from companies participating in the program.

PoDoCo projects consist of two phases: broad research and targeted research. The aim of the first phase is to create far-reaching knowledge on a research topic of interest to both the doctor and the company. The PoDoCo foundation pool offers research grants of 6-12 months for this first phase. After the broad research phase has been completed, the company hires the doctor to deepen the research results and to create company-specific insights during the targeted research phase, which also lasts $6-12$ months and is funded by the industrial partner.

The PoDoCo program has been running since 2015 and, so far, the program has received extremely positive responses from both companies and doctors. For companies, the PoDoCo program offers an opportunity to investigate new strategic openings with the help of talented doctors who are familiar with scientific analysis and synthesis methods and who possess the latest scientific knowledge. For doctors, the PoDoCo program offers an opportunity to work in the private sector, gain industrial experience, and establish important networks with companies. The result is a win-win situation where academic research is supporting the strategic renewal of companies and where doctors gain industrial experience. So far, 64 PoDoCo grants have been awarded, with the first PoDoCo collaboration projects starting in the spring of 2016 and ending during 2017. In the majority of these cases, following the completion of the re- search, the participating doctors have been hired by the companies they collaborated with, meaning that the PoDoCo program has successfully enabled a smooth transition from academia to the private sector. The PoDoCo program has also benefitted participating companies, many of whom have reported that the research conducted during the PoDoCo program has opened new avenues for growth.

\section{Results and Discussion}

The three doctoral education programs presented in this article show that collaborative programs in doctoral education train both industrial actors and academics through boundary-spanning activities.

A key finding of this study was that collaborative doctoral education programs jointly organized by academia and industry clearly facilitate and motivate the doctoral students and graduates to cross the border between academia and industry. A clear majority of the students participating in the programs continued their careers in industry after doctoral graduation.

We also found that the industrial players involved in the collaboration found it particularly beneficial that doctoral students were able to bring new and fresh ideas, innovative mindsets, and new scientific knowledge into the industrial domain. They also appreciated the opportunity to employ the newly graduated doctors into their internal R\&D tasks, which facilitates the commercialization process of the university innovations developed in the doctoral projects. In this manner, the programs help the industrial firms to open doors for potential new employees with high scientific knowledge and skills, whose recruitment increases the firms' internal knowledge resources and capabilities.

The doctoral students underlined the importance of industrial experience and understanding of the industrial way of working that is possible to achieve by participating in the collaboration programs. Thus, such programs lower the threshold for doctoral graduates to transfer to an industrial career.

On the industry side, a related finding was that industrial R\&D staff involving the collaboration were able to familiarize themselves with academic research and education. This, in turn, helps bring industry and academia closer to each other by establishing personallevel contacts and networks and by increasing mutual trust and relational capital, which are key factors to overcome organizational and cultural barriers between 


\section{How Doctoral Students and Graduates Can Facilitate Boundary Spanning between Academia and Industry Leena Kunttu, Essi Huttu, and Yrjö Neuvo}

academia and industry (Bruneel et al., 2010). In this way, the programs facilitate boundary spanning between these two types of institutions (Siegel et al., 2004).

Also, the Nokia Mobile Imaging case showed that jointly organized doctoral education programs may encourage technical staff working in industrial firms to start or continue doctoral studies. In addition to this, getting as many industrial employees as possible to participate the programs as students, mentors, supervisors, lecturers, or audience members can increase positive attitudes and mindsets towards university collaboration, which in turn makes them potential boundary actors (Siegel et al., 2004), and also promotes the research collaboration between universities and industry, as suggested by Kunttu (2017).

\section{Practical Implications}

In this article, we have presented three cases of doctoral education programs aiming at facilitating boundary spanning and mobility between industry and academia. However, these kinds of jointly organized educational programs represent rare examples in doctoral education in Finland and appear to be even rarer within an international context. For this reason, the collaborative practices for facilitating mobility presented in the cases can also be widely utilized in almost all kinds of doctoral education programs, and also in companies that do not have opportunities to participate in doctoral education programs. The key practices identified in this article include:

1. Involving industrial experts in the doctoral education program as guest lecturers, mentors, or supervisors.

2. Providing the doctoral student groups with project work topics that are directly connected to real-world industrial challenges.

3. Providing the doctoral students with opportunities for training or working on the relevant industrial topics during the doctoral studies.

4. Providing the doctoral students with research grants on a topic that is of industrial partner's interest.

5. Providing the doctoral students with the opportunity to continue the research work after graduation as company-internal employees.

\section{Conclusion}

This study sought to better understand how to address the problem that too few young doctors select industrial career after their graduation, despite the fact that these newly graduated doctors possess the latest scientific knowledge that could be applied towards commercial ends in the industrial domain. In this article, we showed that collaborative doctoral education jointly organized by academia and industry is not only able to encourage doctoral students to undertake industrial careers, but also to facilitate wider boundary-spanning activities between these institutions and, in this manner, lower organizational and cultural barriers between them.

All three doctoral education cases presented in this article reveal that industrial R\&D may greatly benefit from participation in collaborative doctoral education by means of new scientific competences, fresh insights, and innovation mindsets provided by doctoral students and newly graduated doctors engaging in the industrial R\&D. As boundary spanners, doctoral students and graduates can form a bridge between academia and industry. By engaging in the doctoral education and postdoctoral transfer programs, industrial firms are able to obtain valuable competences by engaging with doctoral students and graduates who not only transfer scientific knowledge to the firm but also take an active role in integrating and utilizing the knowledge towards commercial ends. In addition to ensuring an effective transfer channel for academic knowledge to industrial purposes, collaboration in these programs involves people from both sides of university-industry boundary in the collaboration and thus facilitates new forms of collaboration and trust building. 


\section{How Doctoral Students and Graduates Can Facilitate Boundary Spanning \\ between Academia and Industry Leena Kunttu, Essi Huttu, and Yrjö Neuvo}

\begin{abstract}
About the Authors
Leena Kunttu received her PhD degree in Information Technology (Signal Processing) from the Tampere University of Technology, Finland, in 2006. Between 2007 and 2012, she served as Senior Manager in an area of innovation at the Nokia Corporation. During her career at Nokia, she led a number of collaborative projects between the company and external research institutes, such as universities. She also led and participated in joint educational activities between Nokia and universities. Since 2015, Dr. Kunttu has served as a researcher in an area of innovation at the University of Vaasa, while also carrying out $\mathrm{PhD}$ studies in industrial innovation. Her current research interests include university-industry collaboration, educational involvement, and the commercialization of university technologies.
\end{abstract}

Essi Huttu is Vice President, Co-Creation at DIMECC Ltd, a Finnish innovation company boosting digital transformation in Finnish industry by joining the forces of companies and universities. In the management team, she leads foresight activities and collaborative $R \& D$ program preparations between companies and universities. Huttu is also responsible for DIMECC co-creation activities designing and managing co-creation services, such as the PoDoCo (PostDocs in Companies) program, to bring postdocs and companies together. Previously, she worked in various development projects in the manufacturing industry. She has also worked as a Researcher in the Department of Industrial Management at Tampere University of Technology, Finland, conducting research in the field of service innovations, product-service solutions, servitization, and organizational transformation towards service business. Huttu holds a Master's Degree in Technology (Industrial Management and Engineering) from Tampere University of Technology.
Yrjö Neuvo is Professor and Research Director at Aalto University, Finland, and Vice Chairman of the Board of Vaisala Corporation. He was Chief Technology Officer and a member of the Group Executive Board of Nokia from 1993-2005, during which time his responsibilities included managing mobile phones R\&D. Before joining Nokia, his 19-year academic career included positions as Professor at Tampere University of Technology, as National Research Professor at the Academy of Finland, and as a visiting professor at University of California, in Santa Barbara, USA. He was Chairman of ARTEMIS JTI Governing Board from 2007-2008, Bureau Member of European Science and Technology Assembly (ESTA) 1994-1997, and General Chairman of the 1988 IEEE International Symposium on Circuits and Systems and of the IEEE International Conference on Communications (ICC 2001). He was Member of Governing Board and its Executive Committee of European Institute of Innovation and Technology from 2008-2012. He is Life Fellow of IEEE, Member of Academia Europeae, the Swedish Academy of Technical Sciences, and two Finnish Academies. In addition to his $\mathrm{PhD}$ degree, which he received from Cornell University in 1974, he holds four honorary doctorates. Asteroid 1938 DN carries his name: Neuvo. 


\section{How Doctoral Students and Graduates Can Facilitate Boundary Spanning between Academia and Industry Leena Kunttu, Essi Huttu, and Yrjö Neuvo}

\section{References}

Ankrah, S., \& Al-Tabbaa, O. 2015. Universities-Industry Collaboration: A Systematic Review. Scandinavian Journal of Management, 31(3): 387-408.

https://doi.org/10.1016/j.scaman.2015.02.003

Ankrah, S., Burgess, T. F., Grimshaw, P., \& Shaw, N. E. 2013. Asking Both University and Industry Actors about Their Engagement in Knowledge Transfer: What Single-Group Studies of Motives Omit. Technovation, 33(2-3): 50-65.

https://doi.org/10.1016/j.technovation.2012.11.001

Auriol, L., Misu, M., \& Freeman, R. A. 2013. Careers of Doctorate Holders: Analysis of Labour Market And Mobility Indicators. OECD DSTI Working Paper DSTI/DOC(2013)4. Paris: Organisation for Economic Co-operation and Development (OECD), Directorate for Science, Technology and Industry (DSTI).

Bruneel, J., D’Este, P., \& Salter, A. 2010. Investigating the Factors that Diminish the Barriers to University-Industry Collaboration. Research Policy, 39(7): 858-868.

https://doi.org/10.1016/j.respol.2010.03.006

Gassmann, O., Enkel, E., \& Chesbrough, H. 2010. The Future of Open Innovation. $R \& D$ Management, 40(3): 213-221.

https://doi.org/10.1111/j.1467-9310.2010.00605.x

Kunttu, L. 2017. Educational Involvement in Innovative University Industry Collaboration. Technology Innovation Management Review, 7(12): 14-23.

https://timreview.ca/article/1124

Laursen, K., \& Salter, A. 2004. Searching High and Low: What Types of Firms Use Universities as a Source of Innovation? Research Policy, 33(8): 1201-1215.

https://doi.org/10.1016/j.respol.2004.07.004

Perkmann, M., Tartari, V., McKelvey, M., Autio, E., Broström, A., D'Este, P., Fini, R., Geuna, A., Grimaldi, R., Hughes, A., Krabel, S., Kitson, M., Llerena, P., Lissoni, F., Salter, A, \& Sobrero, M. 2013. Academic Engagement and Commercialisation: A Review of the Literature on University-Industry Relations. Research Policy, 42(2): 423-442.

https://doi.org/10.1016/j.respol.2012.09.007

Rajalo, S., \& Vadi, M. 2017. University-Industry Innovation Collaboration: Reconceptualization. Technovation, 62-63(April): 42-54.

https://doi.org/10.1016/j.technovation.2017.04.003

Siegel, D. S., Waldman, D. A., Atwater, L. E., \& Link, A. N. 2004. Toward a Model of the Effective Transfer of Scientific Knowledge from Academicians to Practitioners: Qualitative Evidence from the Commercialization of University Technologies. Journal of Engineering and Technology Management, 21(1-2): 115-142. https://doi.org/10.1016/j.jengtecman.2003.12.006

Weckowska, D. M. 2015. Learning in University Technology Transfer Offices: Transactions-Focused and Relations-Focused Approaches to Commercialization of Academic Research. Technovation, 41-42: $62-74$.

https://doi.org/10.1016/j.technovation.2014.11.003
Citation: Kunttu, L., Huttu, E., \& Neuvo, Y. 2018. How Doctoral Students and Graduates Can Facilitate

(cc) BY
Boundary Spanning between Academia and Industry. Technology Innovation Management Review, 8(6): 48-54. http://doi.org/10.22215/timreview/1164

Keywords: knowledge transfer, university-industry collaboration, doctoral education, academic engagement, industrial engagement 


\section{Academic Affiliations and Funding Acknowledgements}

Canadà
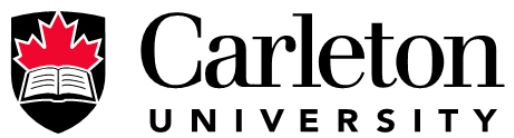

U N I V E R S I T Y

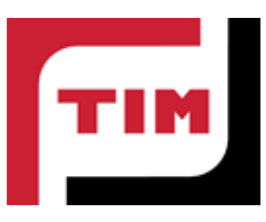

The Federal Economic Development Agency for Southern Ontario (FedDev Ontario; feddevontario.gc.ca) is part of the Innovation, Science and Economic Development portfolio and one of six regional development agencies, each of which helps to address key economic challenges by providing regionallytailored programs, services, knowledge and expertise.

- The TIM Review receives partial funding from FedDev Ontario's Investing in Regional Diversification initiative.

Technology Innovation Management (TIM; timprogram.ca) is an international master's level program at Carleton University in Ottawa, Canada. It leads to a Master of Applied Science (M.A.Sc.) degree, a Master of Engineering (M.Eng.) degree, or a Master of Entrepreneurship (M.Ent.) degree. The objective of this program is to train aspiring entrepreneurs on creating wealth at the early stages of company or opportunity lifecycles.

- The TIM Review is published in association with and receives partial funding from the TIM program. 